\title{
O Mito De Tristão E IsOlda InSCRITo Na ANTIGUIDADE: Contribuições Teórico-Metodológicas Para Além Da Idade MÉDIA
}

\author{
Ana Carolina Pedroso Alteparmakian ${ }^{1}$
}

RESUMO

O artigo se propõe a um levantamento teórico-metodológico, e também historiográfico, de três elementos que permeiam o conteúdo do mito de Tristão e Isolda. O primeiro busca analisar o significado do termo gênero, como instrumento de análise caro à ideia de "mulher medieval"; o segundo visa discutir a compreensão e difusão dos mitos durante a Antiguidade e Idade Média. E, por último, será abordada a interpretação formulada por Jean Markale, em La Femme Celte: amparado sobre a teoria da existência de sociedades ginecocratas pré-históricas, o mitólogo realiza uma análise da personagem Isolda e identifica-a com traços femininos advindos das sociedades célticas. Discutiremos, assim, a importância destes três elementos para o conhecimento mais profundo do mito tristânico, narrativa que se ampara sobre pressupostos anteriores à Idade Média, época de sua (re)emergência.

\section{PALAVRAS-CHAVE}

Gênero; romance; mulheres; mitologia; patriarcado.

\footnotetext{
${ }^{1}$ Mestranda pelo Programa de Pós-Graduação em História Social, Faculdade de Filosofia, Letras e Ciências Humanas da Universidade de São Paulo (FFLCH/USP). Possui Bacharelado e Licenciatura em História pela FFLCH/USP. Membro do LABORA/USP (Laboratório de Estudos sobre Pensamento e Cultura na Idade Média). E-mail: ana.alteparmakian@usp.br e ana.pedroso04@gmail.com.
} 


\section{Introdução}

"O romance, a Igreja e a mulher na Idade Média: as distintas caracterizações de 'Isolda' em Tristan, de Thomas da Inglaterra”, pesquisa de mestrado em andamento, busca realizar uma análise contextualizada da personagem Isolda, a rainha presente nas várias versões dos romances de Tristão e Isolda, escritos e declamados durante a Idade Média. Partindo-se do pressuposto da existência e permanência de um conjunto de ideias cristãs-definidas e difundidas nas sociedades da Europa ocidental pelos chamados Padres da Igreja, nos primeiros séculos cristãos - pretende-se compreender a personagem em questão como uma espécie de "antítese" daquilo que era possivelmente tomado como o status feminino aceitável para o período; ou seja, das ideias que compreendiam o papel feminino na sociedade cristã como necessariamente subjugado e inferior ao masculino.

Para tal objetivo, tem-se buscado delinear os elementos contextuais da época, a chamada Idade Média central (séculos XI a XIII d. C.): as mudanças ocorridas na Inglaterra e territórios angevinos ${ }^{2}$ — tanto em âmbitos político e/ou religioso-que podem, de alguma maneira, ter influenciado na emergência e na composição de uma possível personagem distinta ao "estereótipo" feminino tido como "regra” à época. Essa hipótese sustenta-se a partir da constatação de que as mudanças trazidas com a chamada Reforma Eclesiástica do século XI (conhecida como Reforma Gregoriana) teriam alterado as lógicas de interação entre regnum e sacerdotium por grande parte da Europa ocidental: na Inglaterra, especificamente, a mais provável localidade de produção do roman, a Igreja estaria realizando investidas para aumentar seus espaços de poder durante o reinado de Henrique II.

O conteúdo notadamente não cristão presente na história de Tristão e Isolda chamou atenção de especialistas que se indagaram sobre a proeminência de um romance com temas "pagãos" numa corte cristã, se isto poderia ser entendido como uma espécie de "resistência" por parte da dinastia Plantageneta e sua aristocracia majoritariamente

\footnotetext{
${ }^{2}$ Há uma variedade de trabalhos que atestam as transformações levadas para a Inglaterra após a conquista normanda de 1066: a transferência de uma elite normanda para a ilha - cujas consequências podem ser percebidas através da adoção do francês em território inglês, por exemplo; mudanças na relação da realeza normanda com a Igreja - tanto clero local quanto a Sé romana, ou ainda mudanças com relação ao estatuto jurídico feminino, adequado com os padrões normandos. Uma obra importante de síntese que pode ser verificada é: Harper-Bill e Van Houts (2003). Mas também há clássicos historiográficos que tratam do período anglo-normando na Inglaterra, como: Barlow (1955), Bartlett (2000) e Brooke (1961). Ou ainda o artigo clássico cujo enfoque se dá sobre as consequências da conquista normanda para as mulheres: Stafford (1994, p 221-249).
} 
normanda a esse poder cada vez mais clericalizante advindo dos altos patamares do clero inglês no período (Brooke, 1961, p. 242). Para se trabalhar mais a fundo com tal hipótese, faz-se necessário compreender as consequentes transformações culturais, ocorridas concomitantemente aos vários acontecimentos de âmbito sociopolítico: o surgimento dos chamados roman - escritos, a partir desse período, nas chamadas línguas vernáculas - e a poesia entendida como "amor cortês" (fin' amour), por exemplo, são alguns dos fenômenos a serem compreendidos durante a pesquisa.

O florescimento da Matéria da Bretanha nas regiões peninsulares de ocupação e tradição célticas, também se constitui como um movimento fundamental de ser elucidado, uma vez que a fonte trabalhada durante a pesquisa — o poema octossílabo “Tristan”, cuja autoria é atribuída ao clérigo Thomas da Inglaterra, produzida provavelmente na década de 1170 d. C.- pertence a este movimento que os contemporâneos do século XXI tendem a denominar como "literário". Os romances da Matéria da Bretanha compreendem as histórias do lendário rei Artur e dos cavaleiros da Távola Redonda-dentre eles, Tristão, em algumas versões - mas também algumas histórias paralelas a este ciclo arturiano: os romans tristânicos.

As fontes principais que abordam o tema tristânico são três, escritas em versos e em língua vernácula (francês antigo, geralmente): a versão de Béroul, poeta também da corte anglo-normanda de Henrique II; a de Thomas, já salientada aqui, e a de Gottfried von Strassburg, escrita no início do século XII, que se encontra em alemão antigo. Existem outras versões que apresentam pequenos episódios advindos da legenda tristânica: o Folie Tristan d'Oxford e o Folie Tristan de Berne; ambos são poemas curtos (com cerca de 1000 versos), escritos também em anglo-normando e que seriam próximos, cronologicamente, às versões principais já elucidadas.

De maneira geral, a história trata das infelicidades do casal protagonista, Tristão, cavaleiro ilustre do reino da Cornualha, e Isolda, princesa da Irlanda e, posteriormente, rainha da Cornualha através do casamento com o rei Mark, tio de Tristão ${ }^{3}$. Em uma época não explicitada, o casal apaixonado comete transgressões para poder permanecer juntos e, um desfecho trágico da estória—que conta com a morte de Tristão, ferido em um combate, e a morte seguida de sua amada Isolda, consumida pela tristeza — trouxe aos

${ }^{3} \mathrm{O}$ estudioso do século XIX Joseph Bédier, um dos pioneiros nos estudos tristânicos, formulou uma versão "moderna" para a história do casal apaixonado a partir de distintos acontecimentos presentes nas várias versões medievais do romance. Para mais sobre a história ver: Bédier (2014). 
leitores contemporâneos indagações sobre a possível mensagem que a história quis legar à posteridade (Hunt, 1981, pp. 41-61). Há, dessa forma, uma clara ênfase nas construções psicológicas das personagens, assim como um erotismo nos relatos dos encontros amorosos do casal transgressor-o qual, além de praticar adultério, comete também incesto-; um duplo pecado ao qual pode se acrescentar ainda a dominância e o controle de Isolda sobre o destino de Tristão: uma mulher sábia, astuta e conhecedora de poderes e curas medicinais.

A versão de Thomas da Inglaterra ${ }^{4}$ chegou à contemporaneidade fragmentada. São conhecidos, dessa maneira, somente alguns episódios do que seria o roman completo, distribuídos em cinco manuscritos principais, abrangendo cerca de 3 mil e 300 versos, apreendidos e editados no século XIX: o de Cambridge, o de Sneyd, o de Turin, o de Strasbourg I e um último intitulado de Fin du poème (também conhecido como Douce). Em 1995, fora descoberto por alguns especialistas do tema um outro fragmento, o de Carlisle, que contém cerca de 150 versos. Embora os versos se encontrem muito deteriorados, foi possível identificar que este excerto trata dos primórdios da estória, localizado cronologicamente antes de todos os manuscritos que eram conhecidos e foram trabalhados durante o século XIX.

A caracterização de Isolda da Irlanda na maioria das versões, porém, mais notadamente na de Thomas, suscita um questionamento acerca das relações de gênero que estavam inseridas naquela sociedade - provavelmente na ambientação de produção do roman. Compreender essas relações entre os gêneros, que, supõem-se que estejam por trás da alta sociedade anglo-normanda do período ${ }^{5}$, significa adotar, necessariamente, a teorização que muitos especialistas fizeram sobre o significado de gênero durante o século XX. Este é, dessa forma, o primeiro elemento que deverá aqui ser analisado e apontado como instrumento fundamental do historiador que busca entender esse traço

\footnotetext{
${ }^{4}$ A edição da fonte aqui utilizada é: Marchello-Nizia e Short (1995, p. 123-212).

5 Obviamente que não se busca aqui compreender a "sociedade anglo-normanda" como um elemento estático e/ou homogêneo; e também tal levantamento não se faz pertinente neste artigo. Porém, existem alguns estudos que podem fornecer ao historiador um possível vislumbre das características da sociedade anglo-normanda, semelhante à sociedade francesa, durante a Idade Média. Estes estudos focam nas transformações socioeconômicas, políticas e também culturais que se acredita que tenham feito parte da realidade do século XII. O roman de Tristan compartilha de alguns elementos que podem ter sido presentes na sociedade cortês do período-um caso específico é o elogio à cidade de Londres feita por Thomas, presente no verso 1385 do manuscrito Douce - e também certas práticas culturais que, presentes no roman, podem compor um fator de verossimilhança com o ambiente em que Thomas esteve imerso. Um clássico exemplo que busca encontrar indícios da "vida real" nas narrativas hoje consideradas "literárias" é Kohler (1990).
} 
social do passado: problematizar a ideia de gênero como recurso que vai de encontro a um possível estereótipo da "mulher medieval".

O segundo aspecto que se faz necessário ser comentado aqui e que se refere, de certa maneira, ao conteúdo do roman é a concepção de mito ou, mais detidamente, como as narrativas e tradições que atualmente são designadas como mitológicas podem ser apreendidas e trabalhados pelos pesquisadores das Ciências Humanas. Sabe-se da excepcional importância das narrativas mitológicas da Antiguidade que, imiscuídas na vida social da maioria das civilizações antigas, podem ser entendidas como construtos simbólicos chaves para se compreender as sociedades das quais vieram através de meios orais. Ao que tudo indica, muito semelhante à construção e difusão do mito de Tristão e Isolda, supostamente proveniente de tradições orais de origem céltica.

O terceiro aspecto que deverá ser aqui abordado refere-se ao debate que reemergiu na academia — após seu apogeu durante a década de 1970 — sobre a existência de supostas sociedades pré-históricas, ou primitivas, que detinham um caráter ginecocrata; isto é, em que o feminino ocupava um lugar de proeminência e/ou de igualdade em relação ao masculino. Esta teoria serviu como pressuposto à produção da obra La Femme Celte, do mitólogo Jean Markale (1986), que busca compreender o elemento feminino na cultura e sociedade célticas: ao dedicar um dos capítulos de sua obra à Isolda, caracterizada como um dos estereótipos da "mulher celta"-elaborada através da exposição de relatos mitológicos galeses e irlandeses-, Markale a designa como uma espécie de resistência à sociedade patriarcal que emergiu após o desvanecimento dessas "sociedades femininas" anteriores ao período neolítico ${ }^{6}$.

\section{Gênero: uma contribuição teórico-metodológica à ideia de "mulher medieval"}

"A forma como se manifesta, social e culturalmente, a identidade sexual dos indivíduos" (Ferreira, 2004, pp. 430-431): essa é a definição de gênero que pode ser encontrada no dicionário Aurélio da Língua Portuguesa. Comumente confundido com a definição de sexo (este deliberado mais estritamente a partir do aparato biológico dos indivíduos), o gênero vem sendo apontado como a construção social dos papéis que se costuma atribuir aos sexos (Graves-Brown, 2010, p. 10). Para além do simples significado

\footnotetext{
${ }^{6}$ Markale ampara o desenvolvimento de sua teoria a partir dos estudos de Daninos (1965) e Millet (1970).
} 
do termo gênero, no entanto, existe uma discussão acadêmica que, pelo menos desde o célebre artigo da historiadora estadunidense Joan $\mathrm{Scott}^{7}$, tem ganho espaço nas pesquisas entre as Ciências Humanas e tem redefinido a forma como as temáticas que tangenciam essas construções sociais são trabalhadas pelos pesquisadores.

Às vezes, utilizada erroneamente como sinônimo da História das Mulheres, a História das Relações de Gênero implica um enfoque na maneira como se constroem as relações sociais entre o que é entendido como feminino e como masculino nas diversas sociedades do passado. Este segundo campo busca romper, portanto, com a necessidade de se detectar, necessariamente, uma agência ou um protagonismo feminino dentro dos grandes temas históricos, como geralmente tem realizado a História das Mulheres, emergida de um contexto de movimentos feministas (Tilly, 1994, pp. 29-62); busca-se, na verdade, inscrever o feminino como um elemento dinâmico e constituidor das relações sociais tecidas entre os indivíduos históricos. $\mathrm{O}$ enfoque não se faz mais exclusivamente sobre a mulher ou sobre o homem, mas no possível vislumbre da relação entre ambos; nesses termos, masculinidade e feminilidade, dois atributos socialmente construídos, se constituem, assim, como os principais objetos da chamada História das Relações de Gênero.

Joan Scott postulou, em meados da década de 1980, dois significados essenciais à compreensão do termo gênero, a ser empregado na prática historiográfica: o primeiro significado é de que gênero seria um elemento constitutivo das relações sociais baseado nas diferenças entre os sexos; e o segundo define o termo como uma forma primária de dar sentido às relações de poder (Scott, 1995, p. 86). Ainda segundo Scott, o primeiro significado implicaria em quatro elementos que o historiador deve estar atento ao realizar sua análise: I. os historiadores deveriam compreender os símbolos culturalmente disponíveis nas sociedades do passado que estudam, indagando-se como e em quais contextos estes símbolos seriam utilizados; II. atentar-se à existência de conceitos normativos (isto é, que exprimem interpretações dos significados dos símbolos) que são comumente expressos em doutrinas religiosas, educativas, científicas ou políticas das sociedades em foco e que tomam forma de uma oposição binária fixa; III. essa noção de fixidez, estabelecida por essa posição binária entre os sexos, deve ser rechaçada pelo historiador, o qual deve compreender a natureza do debate ou da repressão que leva a essa

\footnotetext{
${ }^{7}$ Embora o artigo fora publicado na década de 1980, a tradução aqui utilizada é de 1995 (Scott, 1995, pp. 71-99).
} 
aparência de permanência intemporal; IV. é necessário ter ciência da identidade subjetiva do gênero, isto é, de que homens e mulheres reais nem sempre cumprem literalmente as "prescrições" da sociedade em que se encontram, ou definidas por nossas categorias analíticas.

Diante deste quadro teórico-metodológico delineado por Scott é interessante indagar-se: em que medida é possível compreender a "mulher medieval" 8 ? A própria noção fixa que denota a ideia de "mulher medieval" já é algo que se torna rechaçável e, se essa categoria for pensada a partir do segundo e terceiro elementos apresentados por Scott, pode-se vislumbrar as ideias sobre as mulheres que viveram durante o período medieval a partir desses conceitos normativos que foram manifestados, principalmente, através de doutrinas religiosas, por exemplo; no caso da Idade Média ocidental, as dogmáticas, ao que parece, hegemônicas, judaico-cristãs.

Mas é importante não considerar ingenuamente essa posição binária que os escritos do cristianismo primitivo fazem acerca do feminino versus masculino: é necessário, segundo o terceiro elemento de Scott, que o historiador considere as proposições indicadas nessas documentações como produtos de conflitos, e não de um consenso social (Scott, 1995, p. 87). Os motivos dessas classificações binárias, elaboradas pelos Padres da Igreja, podem ajudar o historiador a compreender a natureza desse debate, os estímulos do contexto de produção dessas fontes que podem ter influenciado tais designações acerca do feminino, por exemplo. Mas somente a existência dessas fontes não permitem o historiador a estabelecer a categoria, com aspecto fixo, da "mulher medieval", embora esses escritos tenham influenciado - como é sabido ${ }^{9}$ - toda uma tradição intelectual medieval a estabelecer o papel da "mulher" como inferior em relação ao homem (pelo menos, em tese).

\footnotetext{
${ }^{8}$ A ideia de "mulher medieval" nasce de uma ampla bibliografia que busca focar na maneira como os contemporâneos da Antiguidade Tardia e Idade Média entendiam o sexo feminino; nasce da convenção de que a maioria dos tratados/escritos desta época se referem ao sexo feminino no singular e sempre de maneira subjugante e detrativa, como é o caso dos escritos dos Padres da Igreja. Ademais, os próprios meios midiáticos contemporâneos do século XXI — como jogos, filmes e séries televisivas - tendem a adotar esta representação do feminino, mostrado como necessariamente inferior ao masculino. O feminino medieval, no senso comum, é singular. Para mais ver: Braga (2007), Brown (1990) e Pilosu (1995).

${ }^{9}$ Amparados pelos teóricos do cristianismo primitivo para evocar autoridade, muitos membros do clero permaneceram produzindo escritos, atualmente considerados misóginos, ao longo dos séculos medievais por todo o ocidente. Inclusive, durante os séculos centrais da Idade Média-XI, XII e XIII—pulularam escritos, provenientes de ambientes eclesiásticos, que buscavam justificar a inferioridade feminina; autores como Graciano, Marbod de Rennes, André Capelão, Jacques de Vitry e Walter Map, por exemplo. A coletânea organizada por Blamires (2002) traz trechos fundamentais desses autores no que concerne às opiniões sobre o feminino.
} 
Mare Nostrum, ano 2020, v. 11, n. 1 .

"As estruturas hierárquicas dependem de compreensões generalizadas das assim chamadas relações naturais entre homem e mulher" (Scott, 1995, p. 91): essa constatação refere-se, ademais, ao segundo significado que Scott estabelece para a compreensão de gênero, aquela que o aponta como uma forma de dar significado às relações de poder. Gênero e poder estariam, assim, interconectados e seriam dois elementos que estruturam as organizações, concreta e simbólica, da vida social humana (Scott, 1995, p. 88). Ao ser considerado dentro do arcabouço contextual do cristianismo primitivo, esse aspecto detém sua coerência justamente na conjuntura de estabelecimento dessa nova crença numa dimensão institucional; isto é, a instauração da Igreja como instituição e, portanto, direcionada à tomada de espaços do poder detém uma profunda relação com as designações dos papéis atribuídos aos sexos nesses escritos cristãos primevos.

Assim, num movimento de reciprocidade, essas "novas"10 relações entre os sexos, ensejadas e justificadas pelo cristianismo, seriam uma das formas de sustentar, grosso modo, a legitimação do poder cristão (este político, aliás) —ainda num contexto de difícil fixação, durante a Antiguidade Tardia — e este, por sua vez, determinaria uma manutenção da ordem baseada nestas "relações naturais entre homem e mulher" (naturais porque divinas), entendida como a estrutura básica de qualquer sociedade. Nas palavras da própria autora:

O gênero é uma das referências recorrentes pelas quais o poder político tem sido concebido, legitimado e criticado. Ele não apenas faz referência ao significado da oposição homem/mulher, ele também o estabelece. Para proteger o poder político, a referência deve parecer certa e fixa, fora de toda construção humana, parte da ordem natural ou divina. Desta maneira, a oposição binária e o processo social das relações de gênero tornam-se parte do próprio significado de poder; pôr em questão ou alterar qualquer de seus aspectos ameaça o sistema inteiro. (Scott, 1995, p. 92)

\footnotetext{
${ }^{10}$ É necessária certa cautela ao considerar como "novas" as relações entre os sexos e as designações sobre o feminino realizadas pelos teóricos cristãos da Antiguidade Tardia. É possível que muitas das dogmáticas desenvolvidas pelo cristianismo tenham sido apreendidas das tradições judaicas das quais o próprio cristianismo é proveniente; ademais, é necessário considerar as construções culturais das relações entre os sexos das sociedades não cristãs, isto é, pagãs, provenientes da Antiguidade clássica. Para mais, ver: Bloch (1994) e Fonseca (2013, p. 75-85).
} 
Embora esses discursos de poder dos quais fala Scott, possivelmente amparada sobre uma perspectiva foucaultiana ${ }^{11}$, possam ser úteis ao historiador que busca focar nas possíveis relações de gênero que permearam a Antiguidade Tardia e o início da Idade Média, não há como ter certeza da efetiva aplicação destes discursos em âmbito real. Supõe-se, então, a adoção destes discursos ao longo dos séculos medievais pela maneira que os homens da Idade Média fizeram uso de pressupostos advindos da Antiguidade em outras áreas do cotidiano ${ }^{12}$; quer dizer, em formas mutáveis, estas ideias podem ter feito parte da ambientação do século XII, época de produção de "Tristan”. É dessa maneira que Isolda destoa desta concepção, aparentemente estática, da "mulher medieval" engendrada segundo os ditames de poder do cristianismo primitivo.

\section{Mito: um instrumento de vislumbre à História?}

Um importante recurso à compreensão histórica, principalmente após a chamada História das Mentalidades que esteve em desenvolvimento com a terceira geração do movimento dos Annales, na segunda metade do século XX, são os relatos que atualmente compreendem-se como mitológicos. Antes, porém, faz-se necessário delinear o entendimento que a contemporaneidade tem acerca da concepção de mito; segundo palavras do escritor e pesquisador suíço Denis de Rougemont (1988, p. 18):

Poderíamos dizer, de um modo geral, que um mito é uma história, uma fábula simbólica, simples e tocante, que resume um número infinito de situações mais ou menos análogas. $\mathrm{O}$ mito permite a percepção imediata de determinados tipos de relações constantes, destacando-os do emaranhado das aparências cotidianas. [...]. Num sentido mais restrito, os mitos traduzem as regras de conduta de um grupo social ou religioso. Têm origem, portanto, no elemento sagrado em torno do qual

\footnotetext{
${ }^{11}$ Esta perspectiva adotada por Scott está em consonância com uma ideia desenvolvida pelo filósofo Michel Foucault, segundo a qual os modos de discursos dominantes tenderiam a uma mudança com o passar do tempo, isto é, Foucault nega a ideia de uma continuidade "transhistórica" dos discursos de poder, embora eles possam parecer semelhantes ao longo dos séculos. Para mais ver: Foucault (2000).

${ }^{12}$ A adoção da matéria antiga, em suas diversas formas, é claramente elucidada pelo trabalho clássico de Curtius. O filólogo e historiador apresenta a adoção das artes liberais do trivium e quadrivium durante a Idade Média, sua irradiação nos escritos literários e a importância das autoridades antigas para se validar uma ideia. Para mais ver: Curtius (1996).
} 
Mare Nostrum, ano 2020, v. 11, n. 1 .

se constituiu o grupo. Ele se apresenta como expressão inteiramente anônima de realidades coletivas ou, mais exatamente, comuns. [...]. Mas o caráter mais profundo do mito é o poder que exerce sobre nós, geralmente à nossa revelia. O que faz com que uma história, um acontecimento ou mesmo um personagem se transformem em mitos é precisamente esse domínio que exercem sobre nós, a despeito de nossa vontade.

Embora seja impossível inferir com precisão o que pensavam e como se sentiam os homens e mulheres da Antiguidade e Idade Média com relação a estes relatos e, consequentemente, com a esfera do sagrado, muitos estudiosos acerca de ambos os períodos compartilham a ideia de que não existia qualquer distinção entre as esferas social e religiosa, tal como os indivíduos têm atualmente. $\mathrm{O}$ historiador francês Jean-Pierre Vernant, que se dedicou durante sua carreira ao estudo da Grécia Antiga, é um exemplo desse grupo de especialistas; ao tentar compreender a instância psíquica dos indivíduos da Antiguidade, e suas relações com o cotidiano, Vernant (2009, pp. 7-8) apresenta ao seu leitor uma ideia bastante interessante acerca do sagrado, do mito e da esfera cotidiana:

Entre o religioso e o social, o doméstico e o cívico, portanto, não há oposição nem corte nítido, assim como entre o sobrenatural e natural, divino e mundano. A religião grega não constitui um setor à parte, fechado em seus limites e superpondose à vida familiar, profissional, política ou de lazer, sem confundir-se com ela. Se é cabível falar, quanto à Grécia arcaica e clássica, de "religião cívica", é porque ali o religioso está incluído no social e, reciprocamente, o social, em todos os seus níveis e na diversidade de seus aspectos, é penetrado de ponta a ponta pelo religioso.

Mito, religião e relações sociais, ao que parece, estavam interconectados, levando o pesquisador contemporâneo a identificar as ações dos dois primeiros enredados no terceiro, representando um todo lógico indistinguível aos olhos dos homens e mulheres do que se convencionou denominar “Antiguidade Clássica”. Essas narrativas mitológicas (sublinha-se: "mitológicas" somente ao leitor contemporâneo), eram, ainda segundo 
Vernant (2009, pp. 15-16), difundidas através dos ambientes domésticos e também pelo reconhecimento que os poetas, retentores e aprimoradores de uma tradição oral, detinham naquelas sociedades antigas. A poesia épica grega - e, depois, latina-, que retratava todo um conteúdo oral, caracterizado por essa imersão do sagrado no cotidiano, embasamento do mito, deteve grande repercussão social, seja na Antiguidade, seja nos séculos seguintes (embora com mudanças ${ }^{13}$ ), exercendo o papel de cânone literário à cultura europeia ocidental que se desenvolveu (Curtius, 1996).

É claro, entretanto, que o historiador deve estar sempre atento aos empregos retórico-literários que podem estar presentes nestes relatos, não os aceitando cegamente, e não interpretando seu conteúdo a partir de um viés literal. Como salientou o famoso mitólogo Joseph Campbell (2015, p. 46), os mitos seriam relatos carregados de símbolos que, quando interpretados concretamente, perderiam sua mensagem fundamental; ele propõe, assim, que os mitos sejam compreendidos como "instâncias finais da sabedoria", isto é, da sabedoria dos mistérios profundos da vida (Campbell, 2015, p. 46). No fundo, o propósito "pedagógico" desses relatos mitológicos, sejam de quaisquer sociedades, que funciona como um "modelo de comportamento" (Franco Júnior, 2010, p. 34), também é algo que deve servir ao historiador disposto a realizar uma chamada História das Mentalidades $^{14}$.

Medievalistas, preocupados com a repercussão e a compreensão dos mitos recorrentes na Idade Média, também se lançaram a este campo, buscando compreender como os homens e mulheres do período entendiam esses relatos/narrativas ${ }^{15}$. A esfera do sagrado, ao que parece, manteve-se imiscuída à vida social do ocidente medieval, mas engendrada, a partir da Igreja como instituição e da posterior cristianização de boa parte da Europa, pelo arcabouço narrativo bíblico (Baccega, 2011, p. 222).

\footnotetext{
13 As recepções de conteúdos mitológicos e intelectuais advindos da Antiguidade foram amplamente estudadas por filólogos e historiadores. Para mais ver: Cox e Ward (2006); Copeland (1995) e (2016).

${ }^{14}$ História das Mentalidade aqui faz referência às práticas de um imaginário (ou imaginários) coletivo que possivelmente existiu nos períodos abordados pelo historiador. Embora os relatos mitológicos sejam muito propícios a tal prática historiográfica, é necessário, como nos alerta o historiador José D’Assunção Barros, que uma pluralidade de natureza documental faça parte do ofício do historiador. Para mais ver: Barros (2005).

${ }^{15}$ As categorias de pensamento dos homens e mulheres da Antiguidade eram, para uma corrente historiográfica em específico, semelhante às da Idade Média. Nesta perspectiva, é notável, até o início da Idade Moderna, a existência de pensamentos por analogia (símbolos), que uniam significado e significante na forma de se enxergar o mundo e de denominar as coisas; daí a crença na literalidade dos relatos mitológicos, que não eram distinguidos da vida cotidiana já que não existia uma possível "convenção de ficcionalidade" como emergirá durante o período moderno. Para mais ver: Foucault (2000), Gurevich (1972) e Zumthor (1993).
} 
É notável, como elucida o medievalista Hilário Franco Júnior (2010, p. 135), que o cristianismo coletou boa parte dos resíduos mitológicos e/ou culturais que a própria civilização romana não conseguira absorver quando de seu amplo território imperial; desse movimento de apreensão, o cristianismo ressignificou grande parte dos mitos e símbolos que antes pertenciam às culturas compreendidas atualmente como "pagãs". Contudo, Franco Júnior afirma (2010, p. 135) que o mito tristânico manteve-se menos atingido pelo processo de clericalização, diferentemente do mito arturiano.

Esses resquícios mitológicos "pagãos" sobreviveram e atuaram, a partir de uma simbologia híbrida —isto é, cristã-pagã — na vida sociocultural do ocidente medieval, desenvolvendo aquilo que este historiador definiu como cultura intermediária ${ }^{16}$. Foi a partir desta sobrevivência, ainda segundo Hilário Franco Júnior, que se pode constituir os movimentos "literários" que, durante a Idade Média central (séculos XI a XIII) ensejaram os conteúdos do que ficou conhecido como "amor cortês" e Matéria da Bretanha: temas que abrangem a legenda de Tristão e Isolda (Franco Júnior, 2010, pp. 135-137), narrativa também engendrada segundo a concepção de mito, aliás.

As mudanças trazidas com a Reforma Eclesiástica do século XI, comumente reconhecida como Reforma Gregoriana ${ }^{17}$, grosso modo, buscavam ampliar os poderes da Igreja no âmbito temporal dos reinos cristãos ocidentais; à essa "clericalização" das esferas mundanas da sociedade, as camadas laicas desenvolveram uma contraposição que o medievalista Jacques Le Goff, ensejado pelos trabalhos de Erich Kohler, denominou de "reação folclórica"18. Como uma espécie de movimento anticlerical, essa "reação folclórica" foi constituída através da apreensão de "mitemas" pagãos nas narrativas, advindas de um caráter oral, que foram produzidas nas cortes europeias daquele período: dentre elas, Tristan, de Thomas da Inglaterra. Como elucida o historiador Marcus Baccega (2015, p. 366):

\footnotetext{
${ }^{16}$ Isto é, "intermediária" no sentido em que contempla e se constitui como um ponto de convergência entre elementos de dois polos culturais que deveriam ser entendidos como "opostos": a cultura "popular" (ou vulgar) e a cultura clerical. Para mais, ver: Franco Junior (2010, p. 31)

${ }^{17}$ Para mais sobre a trajetória historiográfica do termo, ver: Rust (2013).

18 O termo "reação folclórica" pode ser encontrado entre os escritos de Jacques Le Goff, para quem a 'renovação literária' dos séculos XI e XII foi a representação da formulação de uma nova cultura, composta pelas e para uma nova mediana aristocracia, inculcada na ordem cavaleiresca, os milites; com intuito de se afastar de uma cultura clerical, esses novos atores sociais teriam compostos uma cultura para si, buscando elementos folclóricos de um tempo remoto e anterior à cristianização. Para mais ver: Le Goff (2014, p. 296, nota 26) e Kohler (1990).
} 
A "reação folclórica" correspondeu à constituição de verdadeiras mitologias de origem - que exercem a função legitimadora de narrativas identitárias - para as casas nobiliárquicas. Isso se deu a partir do apelo a entes fantásticos do imaginário pagão pré-cristão, advindos da cultura oral híbrida céltica, germânica e grecoromana, que se mesclaram no interior da moldura ideológica e retórica do Cristianismo.

Os mitos trazem, portanto, conteúdos que permitem ao historiador "decifrar", de certa maneira, as mentalidades das sociedades do passado. Mas, como salientado, não é através da aceitação acrítica que o historiador conseguirá enveredar às redes de pensamento e de ação em que estavam imersos esses homens e mulheres do passado, e sim estabelecendo critérios interpretativos simbólicos que o ajudem a entender qual mensagem aquele mito quer transmitir que está sendo ocultado por sua interpretação meramente literal. Jean-Pierre Vernant (2009, p. 26) traz em sua obra o "método de decifração" do mito desenvolvido pelo historiador Georges Dumézil:

A decifração do mito, portanto, opera seguindo outros caminhos e responde a outras finalidades que não as do estudo literário. Visa a destrinçar, na própria composição da fábula, a arquitetura conceitual envolvida nesta, os grandes quadros de classificação implicados, as escolhas operadas na decupagem e na codificação do real, a rede de relações que a narrativa institui, por seus procedimentos narrativos, entre os diversos elementos que ela faz intervir na corrente do enredo. Em suma, o mitólogo procura reconstituir o que Dumézil denomina uma “ideologia”, entendida como uma concepção e uma apreciação das grandes forças que, em suas relações mútuas, em seu justo equilíbrio, dominam o mundo —o natural e o sobrenatural—, os homens, a sociedade, fazendo-os ser o que devem ser.

A definição fornecida por Vernant a partir de Dumézil ressalta a importância da utilização do mito como meio de vislumbre à sociedade que o criou. Parece que, ao 
Mare Nostrum, ano 2020, v. 11, n. 1 .

mesmo tempo que condiciona certas formas de comportamento na sociedade, é condicionado por esta, num intenso movimento de reciprocidade que pode compor os traços procurados pelo historiador. Além disto, o mito atuante como veículo pedagógico consegue enunciar aos seus ouvintes os possíveis discursos de poder que estão intrínsecos a ele-a "ideologia", de que fala Dumézil. As relações de gênero constituintes das sociedades originárias destas narrativas mitológicas podem estar, ainda que implicitamente, enveredadas nestes discursos de poder e, consequentemente, nesta lógica condicionante e condicionadora, ao mesmo tempo, que é o mito.

\section{A Isolda segundo Jean Markale: resquício de uma sociedade ginecocrata céltica?}

Jean Markale, pseudônimo do escritor, mitólogo e poeta Jean Bertrand, buscou traçar, nos anos 1970, certas caracterizações acerca do entendimento sobre o feminino entre as sociedades célticas. Para tal, utilizou-se intensamente do arcabouço mitológico disponível daquela cultura. Este material, segundo ele, é fundamental à compreensão dos caminhos históricos daqueles povos, os quais enxergavam o mito como sinônimo da história (Markale, 1986, p. 17). Como já salientado, Markale traz à discussão, em um de seus capítulos (1986, pp. 201-243), a personagem Isolda, rainha irlandesa, protagonista das versões do romance de Tristão e Isolda; a partir da exposição de muitos traços culturais e mitológicos dos "celtas", o autor afirma a distinção de Isolda graças à sua construção realizada através de uma "concepção" céltica do feminino.

Antes, porém, faz-se necessária a apresentação da teoria segundo a qual Markale baseia toda sua construção argumentativa para escrever La Femme Celte: a ideia, muito em voga a partir dos anos 1960, de que teriam existido sociedades pré-históricas de organização ginecocrata-isto é, em que o sexo feminino detém certa proeminência na estrutura social — antes da emergência do que ficou conhecido como "patriarcado"19. Esta é uma discussão iniciada em meados do século XIX, que remete aos estudos do jurista

\footnotetext{
${ }^{19}$ O patriarcado é definido da seguinte maneira pela autora Françoise D’Eaubonne: “O patriarcado é um regime baseado na célula familiar onde o homem adquire sua primeira importância a partir do fato de ser o procriador e o rei desta pequena comunidade, constituída pelo receptáculo de sua semente divina (esse "vaso" que sem ele seria "de pecado", como nos vaticínios dos teólogos da Igreja cristã), e pelos produtos desta botânica íntima, os filhos, herdeiros da propriedade privada que ele lhes transmitirá. Esta é a razão por que deve ser rigorosamente vigiada a pureza do vaso em questão.” In: Eaubonne (1977, p. 129). Existe, no entanto, uma discussão acerca do significado de "patriarcado" dentro da corrente feminista de pensamento. Para mais, ver Morgante e Nader (2014).
} 
suíço Johan Jacob Bachofen (1815-1887) que, na década de 1860, publicou a obra Das Mutterrecht Eine Untersuchung über die Gynaikokratie der alten Welt nach ihrer religiösen und rechtlichen Natur (que pode ser traduzida como Matriarcado: investigação sobre a ginecocracia do mundo antigo em seus aspectos religiosos e jurídicos).

Ao levantar uma investigação sobre as civilizações pré-históricas, realizada através dos mais diversos tipos de fontes (arqueológicas, pictóricas, mitológicas, escritas), Bachofen delineia como poderiam ser caracterizadas essas sociedades (localizadas nas atuais Europa e Ásia), consideradas por ele de uma preponderância feminina. Tal consideração se deu graças à identificação, por Bachofen, de dois aspectos: ao fato de que (1) as transmissões de heranças se dariam pela linhagem materna e (2) pela abundância, em certas regiões e em períodos específicos, de estatuetas pré-históricas que estariam representando o feminino, as conhecidas "vênus pré-históricas"; tais estatuetas seriam referentes ao culto da divindade feminina suprema, reconhecida pelos estudiosos como Deusa Mãe ${ }^{20}$.

O trabalho de Bachofen foi fundamental para se criar a teoria da existência de um "matriarcado pré-histórico" 21 , ideia que seria retomada posteriormente durante o século XX. Seguido pela famosa obra de Friedrich Engels, A Origem da Família, da Propriedade Privada e do Estado, de 1884, Bachofen inaugurou, portanto, uma teoria dentro da academia que seria retomada, a partir de um viés diferente, principalmente por autoras feministas que buscavam justificar a igualdade entre os sexos, cerne da maioria das correntes de pensamento feminista, com essa teoria das sociedades ginecocratas. Uma dessas autoras, que escreve em meados da década de 1970, é a escritora e filósofa feminista francesa Françoise D’Eaubonne.

Em Les femmes avant le patriarcat, de 1976, Eaubonne estabelece que foram dois os processos fundamentais a instaurarem o patriarcado ainda durante o período neolítico: a substituição de uma agricultura "de enxada", caracterizada por ela como feminina, pela agricultura de arado, instrumento caracterizado pela autora como de caráter masculino ${ }^{22}$,

\footnotetext{
${ }^{20}$ Para mais, ver: Rossi (2009, p. 273-293).

${ }^{21}$ Para mais ver: Georgoudi em Duby e Perrot (1990, p. 569-589).

22 É importante destacar que as definições deste primeiro processo, apontado por Eaubonne como as mudanças nas formas da agricultura, tem uma singular relação com a teoria ecofeminista desenvolvida por esta estudiosa. Durante toda sua obra, Eaubonne ratifica o caráter ambicioso, produtivista e destruidor do patriarcado, levando o leitor à compreender que as invenções e lideranças masculinas são nocivas ao meio ambiente por deterem uma outra forma de lidar com a natureza; distinta da forma feminina de lidar com a
} 
e a tomada de consciência, pelos homens, de seu papel no processo de paternidade (Eaubonne, 1977, pp. 9-10); ambos teriam ocorrido entre 5000 e 3000 a. C.. Eaubonne realiza, para retificação de sua teoria regida por esses dois processos históricos apresentados, a análise de —mais uma vez-relatos mitológicos e os desenvolvimentos técnicos de várias civilizações, tanto da pré-história quanto da Antiguidade.

A segunda parte de seu livro busca expor, mesmo após a ocorrência desses dois processos que liquidavam a proeminência feminina, como traços significativos dessas sociedades femininas ainda teriam resistido em algumas localidades, como em Creta, em Éfeso, no Egito e entre as sociedades célticas, civilizações que ela denominou de “semipatriarcados" (Eaubonne, 1977, pp. 131-211). Uma vez que o enfoque aqui é o entendimento do feminino dentro dessas sociedades célticas, é interessante que sejam apresentados alguns elementos que caracterizariam esses povos chamados genericamente como "celtas".

Embora existam outros campos de estudos que se dediquem ao aprendizado acerca dos povos celtas, a arqueologia se sobressai de forma importante, principalmente a partir dos estudos pioneiros da arqueóloga Marija Gimbutas (1999, pp. 178-179, tradução nossa), que elucida:

Os celtas constituem uma das interessantes culturas de língua indo-europeia que se formaram a partir do encontro de culturas indo-europeias e da velha Europa durante a Idade do Bronze. De acordo com evidências arqueológicas, as tribos celtas migraram para o sul e oeste de sua terra natal na Europa central nos séculos XII a XI a. C., estabelecendo-se na França moderna e na Península Ibérica. Nos séculos IX e VIII, eles se mudaram pela Europa, principalmente para o oeste. Eles ganharam destaque durante os séculos VIII e VII a.C. e pelos séculos IV a III a.C., os celtas haviam coberto grande parte da Europa. Consequentemente, eles influenciaram

terra e com os recursos naturais, as práticas que vêm com o patriarcado não enxergariam a natureza como uma complementaridade dos seres humanos, e sim como subordinada a estes. A invenção do arado caracterizada como masculina é explicada, assim, por esta relação destrutiva que o homem teria com o meio ambiente; sendo o arado/charrua uma representação de produtividade e superexploração do solo. Para mais ver: Papunen (2014). 
Ana Alteparmakian. O mito de Tristão e Isolda inscrito na Antiguidade.

significativamente o desenvolvimento da cultura europeia subsequente, contribuindo com um conhecimento avançado em metalurgia e um corpo significativo de literatura oral antiga.

Gimbutas cunha o termo "Antiga Europa" para definir a cultura neolítica que existira antes das conquistas indo-europeias; a cultura que seria definida, majoritariamente, pelos cultos à Deusa Mãe, divindade feminina suprema. Segundo ela, um dos traços marcantes da contribuição dessa cultura à posterior cultura céltica seria o alto status feminino estruturado naquelas sociedades que podem ser atestados através, por exemplo, de práticas funerárias específicas e arte religiosa, ambas ligada ao feminino, encontradas nas ilhas britânicas (Gimbutas, 1999, pp. 179).

Os pesquisadores dispõem, principalmente, de narrativas mitológicas - geralmente transcritas muitos anos depois ${ }^{23}$ — e também de material arqueológico para acessarem um conhecimento, ainda nebuloso, sobre os povos celtas. A ausência de documentação escrita diretamente desses povos causa certos receios em se afirmarem caracterizações e fatos mais nítidos sobre esta cultura. Entretanto, alguns códigos de leis (Eaubonne, 1977, p. 139), por exemplo, advindos de regiões de tradição céltica, são utilizados para se compreender suas organizações social e jurídica; esses materiais escritos, provavelmente de registro posterior às práticas descritas, juntamente com artefatos arqueológicos corroboram, ademais, para se compreender a presença da importância da linhagem matrilinear, por exemplo (Gimbutas, 1999, p. 122).

Os estudos de Gimbutas - que fomentaram ainda mais toda esta teoria acerca das sociedades ginecocratas pré-históricas, desenvolvida na segunda metade do século $\mathrm{XX}$ corroboram para estas afirmações acerca da "matrilinearidade" (muitas vezes entendida como um dos elementos destas sociedades "matriarcais"), como é possível vislumbrar numa passagem de uma de suas obras:

Os celtas chamavam a grande deusa de Matrona. Algumas inscrições levam o nome matronae, "as mães", e frequentemente retratam a deusa como uma tríade, um

\footnotetext{
${ }^{23}$ Gimbutas afirma que a cultura tradicional oral irlandesa só ganharia suas primeiras versões escritas após o processo de cristianização daquela região, ocorrida por volta do século V d. C. Ver: Gimbutas (1999, p. 184).
} 
Mare Nostrum, ano 2020, v. 11, n. 1 .

grupo de três. Eles carregam cestas de frutas, cornucópias e bebês. Em uma inscrição gaulesa recentemente descoberta, a deusa é chamada Rigantona, "a grande rainha"; esse nome aparece no galês Mabinogi como Rhiannon. No Mabinogi existe o personagem Mabon ap Modron: isto é, Maponos, filho de Matrona. Maponos, "o jovem" ou "juventude divina", é um deus gaulês e britânico. O fato de ele derivar o nome de sua mãe enfatiza a importância da linha feminina. (Gimbutas, 1999, p. 183, tradução nossa)

Eaubonne (1977, p. 131), por sua vez, estabelece traços do antigo Direito das Mães nas sociedades célticas através dos relatos romanos: estes, por se originarem de uma sociedade de nítido caráter patriarcal, revelam um desprezo com relação às práticas dos recém conquistados territórios de tradição celta, muito distintos do que eram previstos no Direito romano, levando a autora a concluir essa valorização dos princípios femininos entre os celtas.

Os relatos do historiador romano Tácito sobre a ocupação, por mulheres, de cargos de liderança entre os celtas são utilizados por Eaubonne (1977, pp. 136-137). Ela os utiliza para entrar na discussão acerca da organização social céltica que, segundo ela, seria semelhante às organizações greco-romanas, os chamados gens, existindo, no entanto, como principal diferença a posse comum da terra (Eaubonne, 1977, p. 136). A autora, por suas nítidas influências marxistas adquiridas durante sua formação, explica que essa posse comum da terra - regida a partir da existência de um magistrado eleito pela comunidade, cuja função era oferecer e organizar o usufruto da terra — foi uma característica importante para se frear a exploração de um sexo pelo outro.

Os estudos historiográficos que abordam em seu cerne essa teoria das sociedades "femininas" pré-históricas foram, portanto, a base fundamental da obra de Markale que, a partir da exposição de um contexto histórico referente aos povos celtas, identifica, numa ampla variedade de mitos de origens galesa, irlandesa e bretã, "estereótipos" comuns a todos eles em relação às personagens femininas, quase sempre as protagonistas das histórias. Dentre essas histórias, Markale apresenta a famosa lenda do folclore irlandês do casal Diarmaid e Grainne; narrativa na qual, grosso modo, também há a presença de um triângulo amoroso, como em Tristão e Isolda: Grainne, filha do rei da Irlanda, Cormac 
Mac Art, prometida ao líder guerreiro mais velho Fionn Mac Cumhaill, apaixona-se por um dos guerreiros e amigo deste líder, Diarmaid.

Entretanto, não é somente a presença do triângulo amoroso e as coincidências das localidades das histórias que podem chamar atenção. Segundo Markale, há três elementos essenciais que, ao corresponderem à concepção céltica do feminino, trabalham em prol do desenvolvimento de ambas as histórias. São eles: a presença do chamado geis irlandês, uma espécie de "feitiço" ou profecia que é realizado por uma mulher poderosa e que tem consequências sérias ao destino de quem o recebeu; o papel determinante que as mulheres das histórias possuem no desenrolar das narrativas e, por último, a presença de uma "deusa tirânica", de natureza solar, e que determina o destino do homem que está ligado à ela (Markale, 1986, p. 212).

Markale (1986, p. 216) endossa o seguinte significado à compreensão de geis céltico:

Uma vez que influencia o destino de sua vítima, ele não pode ser lançado levianamente, apenas por uma razão muito séria; é um tipo de proibição imposta a uma pessoa em particular, como resultado de certos eventos, e deixa uma marca definitiva. Alguém que viola um "geis" está em sérios problemas e pode ter uma morte dolorosa, até mesmo odiosa e vergonhosa, porque o peso, moral e social, da proibição, coloca o infrator fora da ordem social estabelecida.

Nestes termos ele caracteriza o filtro mágico, a poção de amor bebida por engano por Tristão e Isolda, como um possível geis céltico. O poder deste tipo de "feitiço" estaria sob jurisdição humana, mas também divina, fazendo o indivíduo que recebeu o geis esquecer de suas obrigações e colocar o desejo de quem o lançou em primeiro plano: era esse, ao que parece, o significado para as sociedades célticas. O geis teria sido, portanto, adaptado aos ouvintes do século XII, no formato de uma poção mágica, uma vez que, segundo Markale (1986, p. 216), a moralidade cristã em curso na época não teria permitido que uma protagonista de uma narrativa com ampla difusão tomasse decisões tão moralmente tortuosas por si só, isto é, conscientemente. 
Mare Nostrum, ano 2020, v. 11, n. 1 .

A poção funciona, assim, como uma espécie de meio para travar a responsabilidade do casal protagonista, praticante de adultério, mas também de incesto (Doggett, 2009, p. 107). Uma forma de trazer simpatia ao sofrível casal, como salienta Markale (1986, p. 216). Através do geis, ademais, Isolda e Grainne exercem total controle sobre seus amados: Tristão e Diarmaid são "forçados"- este último talvez mais—a amá-las. Markale ressalta que este é o segundo aspecto que poderia defini-las como o "estereótipo" da mulher celta: o tema da mulher iniciadora e transformadora. De fato, em ambas as narrativas são as mulheres que dão início àquela relação proibida, tomando alguma iniciativa fundamental; Isolda, em especial, inicia sexualmente Tristão, metaforicamente fazendo nascer um "novo homem"24, algo que Markale considera um aspecto expressivamente importante: a sacralidade do nascimento, embora metafórico; ato necessariamente transformador que estaria vinculado, sempre, ao feminino.

Esta mulher iniciadora da qual fala Markale se coloca, assim, como uma aparente contradição com a ideia que a sociedade cristã medieval detinha acerca do sexo feminino. Se for pensada a partir das estruturas daquilo que foi chamado "patriarcado", a mulher iniciadora é, ao que parece, um ser um tanto estranho àquilo, mas também ambíguo, porque, pelo menos dentro das sociedades cristãs, à mulher são atribuídos papéis dialéticos, contraditórios, mas complementares. Quer dizer, ao mesmo tempo que ela deve se calar e se colocar como subserviente ao homem, uma vez que a ela é atribuída a culpa pela Queda do ser humano do Éden (fato mitológico que a coloca como iniciadora também, sendo sua inferioridade a consequência de seu ato primevo necessariamente maléfico ${ }^{25}$ ), ela também é vista como meio de redenção aos pecados cometidos a partir de Eva, redenção simbolizada no culto à Virgem Maria (Bloch, 1994, pp. 77-110; Franco Júnior, 2010, pp. 146-147) ${ }^{26}$.

Essas concepções apresentam, dessa forma, a natureza feminina como atrelada ao impulso iniciador, seja ele para o bem, seja para o mal. Característica eminentemente

\footnotetext{
${ }^{24} \mathrm{O}$ estudioso Leonardo Hincapié, que também investigou sobre as caracterizações das três Isoldas existentes na legenda (Isolda, a mãe; Isolda, a Loura, e Isolda das Mãos Brancas), também ressalta esse tema que cerca principalmente a rainha Isolda, a Loura: a rainha como iniciadora, sexual e amorosa, de Tristão, proporcionando-lhe um outro nascimento. Para mais, ver: Hincapié (2013, p. 17-34).

${ }^{25}$ Para se compreender melhor a consolidação da tradição latina cristã durante a Antiguidade Tardia e as concepções acerca do feminino, ver: Brown (1990).

${ }^{26}$ Em "Tristan" de Thomas, Isolda parece representar também uma forma de redenção, ao mesmo tempo que figura como uma representação de poder, já que é a única conhecedora de curas medicinais que podem salvar Tristan, ferido em batalha e agonizando nos versos finais do poema: ela é poderosa por deter esse conhecimento, que incide sobre o destino de Tristan, mas também é a redenção dos pecados cometidos por ambos.
} 
presente no que os estudiosos apontaram como a divindade suprema de sociedades primitivas, a Deusa Mãe, identificada como divindade solar: este seria o terceiro aspecto identificado por Markale. O mitólogo nomeia este terceiro aspecto de The Mistress of the Orchard (“A Dama do Jardim”), parecendo referir-se às cenas, nas várias versões, em que os amantes se encontram às escondidas num jardim reservado próximo ao castelo de Mark ${ }^{27}$; o jardim, no caso, seria entendido, metaforicamente, como um "microcosmo" no qual Isolda expandiria toda sua influência e soberania, "iluminando" esse local de encontro amoroso com sua presença solar.

Este aspecto levantado por Markale remete à discussão acerca do caráter antagônico que se estabeleceu entre os chamados "deuses olímpicos"—ligados ao céu—e os "deuses ctônicos"- - ligados à terra, ou ao subterrâneo-(no caso grego), constitui uma discussão entre os especialistas da religiosidade antiga (Burkert, 1993, pp. 388-393). Esse antagonismo divino remete, ademais, à elementos expostos na obra de Eaubonne nos quais ela aponta que, no início dos tempos, nas primeiras organizações sociais que ela crê terem sido femininas - um momento ainda obscuro — o feminino era ligado ao céu e, portanto, ao Sol, enquanto que o masculino seria ligado à terra e, assim, à Lua (Eaubonne, 1977, p. 41).

A lógica teria se invertido com a emergência do patriarcado — que atribui o caráter solar ao deus grego Apollo, por exemplo - mas, ao que parece, alguns resquícios dessa lógica primordial teriam resistido nas sociedades denominadas por ela de semipatriarcais. Markale (1986, p. 240) ressalta também essa viragem que teria ocorrido no entendimento dos caráteres das divindades: ao iniciar a discussão salientando que a palavra "sol” nas línguas célticas e germânicas seriam de gênero feminino, o autor postula a inversão que teria ocorrido:

O destino da deusa do sol estava indissoluvelmente ligado à rebelião do homem contra a mulher, o que levava o poder a ser investido numa sociedade dominada pelos homens, e não na ginecocracia. Houve uma inversão total dos valores religiosos, sendo as divindades originalmente femininas substituídas por

\footnotetext{
${ }^{27} \mathrm{Na}$ versão de Thomas da Inglaterra, o jardim/bosque aparece nos episódios iniciais, encontrado no manuscrito de Cambridge, em que o casal é surpreendido pelo rei Mark e, logo após se darem conta, Tristão impõe a si mesmo um exílio, separando o casal e dando início aos dramas mais profundos da narrativa.
} 
Mare Nostrum, ano 2020, v. 11, n. 1 .

divindades masculinas adaptadas às novas estruturas sociais, das quais o paradigma é Apollo. (Markale, 1986, p. 240, tradução nossa)

Não há incoerência em trazer estas discussões à temática de Tristão e Isolda: conquanto o conteúdo tristânico tenha se manifestado durante a Idade Média, os especialistas do tema ${ }^{28}$ sugerem que o mito pode ter sido formulado ainda durante a Antiguidade Tardia e passado por reformulações para ser adaptado às necessidades do público no período medieval. Neste entendimento, o mito tristânico funcionaria como um emaranhado de tradições possivelmente advinda da época que os historiadores consentiram em chamar de "Antiguidade".

E, embora estas características estejam implícitas no mito tristânico, sendo de dificultosa identificação, o conhecimento das mitologias dos povos antigos se faz muito frutífero ao historiador que se debruça sobre a compreensão do trágico casal apaixonado, principalmente para realizar um exercício de interdisciplinaridade como realizou Markale. Dessa maneira, ao concluir o raciocínio de Markale aqui exposto: a qualidade de divindade solar dada à Isolda e a outras heroínas célticas dá a elas o aspecto tirânico através do qual elas detêm o poder e podem impor o geis; elas têm sob seu comando uma autoridade incondicional. Segundo este entendimento colocado por Markale, o poder de reger os acontecimentos sobre a vida e a morte seria, assim, o principal atributo da divindade solar presente nas sociedades antigas.

O poder sobre a vida e a morte é um atributo das Isoldas da legenda tristânica elucidado por Leonardo Hincapié, estudioso mais recente sobre o feminino no tema tristânico. Embora Hincapié não tanja no tema da divindade solar, ele identifica, na tríade representada por Isolda, a Mãe, Isolda, a Loura e Isolda das Mãos Brancas, uma analogia com certas divindades femininas também representadas em tríade dentro das tradições célticas, como, por exemplo, a lenda das três Machas que justificam os nomes de três lugares importantes para a história irlandesa (Hincapié, 2011, pp. 20-21; Waddell, 2018,

\footnotetext{
${ }^{28} \mathrm{O}$ trabalho pioneiro de Gaston Paris (1899) salientou a origem antiga do mito tristânico, assim como o associou, através de semelhanças nas narrativas, às epopeias clássicas da Antiguidade (Paris, 1899, p. 131139). As origens antigas do conteúdo tristânico foram, pela maioria dos estudiosos, localizadas nas regiões de ocupação céltica; dessa forma, a maioria destes especialistas associou conteúdo do folclore e mitologia irlandeses às variantes das narrativas de Tristan. Para mais ver: Schoepperle (1913), Newstead (1959) e Johnson (2012). As narrativas arturianas apareceram em escritos da Antiguidade Tardia e Alta Idade Média, levando os estudiosos a localizarem a precoce existência destas personagens (tanto Artur quanto os cavaleiros da Távola Redonda, incluindo Tristan) já nos primórdios da Idade Média, aparecendo em escritos do cronista Gildas, De excidio et conquestus Britanniae (c. 560) e em Beda, Historia Ecclesiastica Gentis Anglorum (c. 731). Ver: Faletra (2014).
} 
pp. 124-125), sempre influenciando os destinos das demais personagens da narrativa mitológica, mas principalmente dos heróis.

O mito literário de Tristão e Isolda tem um traço dessa antiga concepção mitológica celta. Já observamos a importância dos nomes na mitologia, no folclore, nas narrativas tradicionais e literatura medievais. Portanto, consideramos que as três Isoldas estão de acordo com esta aparição em tríade de uma mesma personagem, aparição atestada na mitologia celta e, em particular, em sua versão irlandesa. No entanto, este caso difere do dos personagens mencionados acima por Vendryes: nenhuma irmã gêmea, nenhuma aparição simultânea na mesma aventura, nenhum fim semelhante. Isolda não seria, portanto, em suas raízes míticas, uma deusa protetora, nem uma líder ou símbolo de uma tribo. O caso de Isolda é bastante semelhante ao da aparição literária da deusa Macha, ou seja, três personagens relativamente independentes para os quais, no fundo mitológico, é possível vislumbrar a mesma identidade. (Hincapié, 2011, p. 23, tradução nossa)

Diferentemente de Jean Markale, Hincapié aborda as três Isoldas como faces de uma mesma personagem: ele enxerga Isolda, a Loura—o par romântico de Tristão—como uma espécie de síntese das outras duas Isoldas. Sua mãe, chamada de Isolda em algumas versões — que lhe transmitiu os saberes de cura fundamentais ao desenrolar da trama, já que era somente a rainha que curaria o cavaleiro de sua derradeira ferida-e sua rival, Isolda das Mãos Brancas, cujo ato de perfídia final leva o herói à morte. Isolda teria, assim, um papel fundamental dentro da narrativa, influenciando sobremaneira o destino de Tristão: é sua amante, levando-o ao caminho erotizado de se tornar um novo homem; é sua cura, já que a vida do cavaleiro estaria em suas mãos em algumas passagens cruciais da estória, mas é também sua algoz, visto que o amor por ela despertado, juntamente com o ciúme de sua rival, o levou à morte ${ }^{29}$.

${ }^{29}$ Nos episódios finais da narrativa pelo menos na versão de Thomas, Tristão, ferido em uma batalha e separado de Isolda sua amada, pede ao seu cunhado e amigo, Kaherdin, que vá buscar Isolda na Cornualha, pois somente ela saberia curá-lo do veneno da espada que o atingira. O amigo teria demorado 40 dias na empreitada-20 dias para ir e 20 para voltar com Isolda à Bretanha, onde estava Tristão, ferido- 
Mare Nostrum, ano 2020, v. 11, n. 1 .

A influência sobre os destinos humanos é algo salientado por Eaubonne (1977, p. 228), assim como o conhecimento feminino acerca da natureza. Conquanto tais atributos possam parecer genéricos e amplos demais, eles não devem ser entendidos como meras coincidências se a influência dessas possíveis sociedades ginecocratas for considerada como reflexo nos arcabouços mitológicos das sociedades antigas. Esses poderes e conhecimentos das Isoldas parecem fazer parte, dentro desta lógica, de todo o construto das atribuições de gênero que o ocidente desenvolveu nos séculos seguintes à esta emergência do que foi entendido como "patriarcado": conservou-se esta mentalidade de que a natureza (e os conhecimentos advindos dela) estaria ligada ao que a sociedade entende como feminino (Doggett, 2009). Assim como a perfídia, elemento atribuído ao feminino, esteve presente na atitude derradeira de Isolda das Mãos Brancas. A ambiguidade atribuída ao feminino (Bloch, 1994, pp. 77-110) não deixa de estar presente e se constitui como uma chave interpretativa coerente.

\section{Considerações finais}

Os conteúdos históricos aqui abordados e apresentados segundo seus tratamentos historiográficos mostraram-se frutíferos para se compreender os aspectos da Antiguidade que podem, ainda que modificados, terem estado presentes durante a Idade Média, sendo refletidos em suas relações sociais. Buscou-se demonstrar de que forma o conceito de gênero apresentou-se como peça-chave à conceituação crítica da ideia de "mulher medieval". É necessário questionar o parâmetro de que a "mulher medieval" deveria encaixar-se aos ditames postulados pelas dogmáticas cristãs da Antiguidade Tardia; ditames que, através de reapropriações clericais ao longo dos séculos, teriam delineado certas formas de comportamento tidas como aceitáveis às mulheres do período. Embora essa concepção ainda seja, de certa maneira, endossada pela documentação, a ideia de

enfrentando vários tipos de adversidades e desastres naturais. A instrução que Tristão lhe dera assim que chegasse à costa bretã era de que se Isolda estivesse à bordo, velas brancas fossem içadas, caso ela tivesse se negado à vir, velas negras deveriam estar à mostra do navio; o que eles não sabiam era que Isolda das Mãos Brancas, a princesa da Bretanha e esposa legítima de Tristão ouvira a conversa com essas informações. Com o retorno de Kaherdin, a esposa de Tristão mente ao ferido sobre a cor das velas, levando o herói a morrer de desgosto por acreditar que sua amada tinha recusado a salvá-lo. Quando chega à Bretanha, a amada de Tristão sabe da notícia e, encontrando seu corpo, morre entrelaçada nos braços do amado. Este arquétipo que traz as velas brancas como referência à vida e as velas negras como referências à morte pode ser encontrado também no mito grego de Teseu. A influência do mito grego sobre o mito tristânico é salientado por alguns autores, ver: Péron (2016). 
gênero, como formulada pela pensadora Joan Scott, no entanto, possibilitou uma maior compreensão à tal "distribuição" dos papéis aos sexos ao possibilitar o vislumbre de um conceito não estático e não tido como regra como denota a ideia de "mulher medieval".

A relação entre os gêneros - isto é, entre aquilo que se entende, social e culturalmente, por masculino e feminino-constitui um todo lógico que não deve ser suplantado pelo direcionamento exclusivo às personagens femininas. Assim, é importante que se enxergue a relação entre ambos, buscando compreender a partir de quais mecanismos essa relação se consolidou e quais suas implicações sociais na época estudada. É imprescindível, dessa forma, que se considere não a "mulher medieval", mas as mulheres e homens que viveram durante a Idade Média e estavam em constante construção de relações sociais que determinavam as formas de vida de ambos. Em outros termos: se Isolda é distinta das mulheres reais que viveram na época de produção da narrativa, é importante que se constate quais as relações socioculturais e as normatizações ${ }^{30}$ — sejam elas consensuais ou conflituosas — em que a personagem esteve enveredada e quais ações e organizações sociais a possibilitaram praticar tais atos inconsequentes de amor e rebeldia.

É necessário, entretanto, que se entenda em que medida era possível adotar atitudes como as da Isolda, uma vez que eles se localizam na esfera (para nós, contemporâneos do século XXI), considerada mitológica. Isolda é, segundo Markale (1986, p. 207), a representação de rebeldia contra a sociedade patriarcal vigente, a qual a prendia às normas que a impediam de exercer sua liberdade como mulher. Ela poderia ser real ou é uma personagem idealizada do poeta que reformulou a narrativa a partir da tradição oral? "O mito pode muito bem ser uma história falsa sobre feitos reais”, diz Jean Markale (1969, p. 8). É a partir deste paradigma, de fundamental importância às sociedades antigas e medievais, que se buscou suscitar a possibilidade de vislumbrar a História através de seus mitos. Não como reflexos do real, mas do verossímil, do factível: esta história poderia ter acontecido, inclusive até com seus elementos mágicos.

\footnotetext{
${ }^{30}$ Obviamente o escopo deste artigo não se propõe a tal exercício, e sim ao levantamento dos instrumentos teórico-metodológicos para tal prática (daí a análise do "gênero" como instrumento, abordada no primeiro tópico), que deve ser realizada durante o desenvolvimento da pesquisa de mestrado elucidada durante a introdução. O recorte aqui adotado permite que a pesquisa amplie e identifique as conexões socioculturais, sobretudo, com a área de estudos da Antiguidade, sendo este recorte uma ferramenta analítica complementar aos pressupostos historiográficos nos quais a pesquisa se baseou.
} 
A cristianização não impedira tão estritamente, assim, que as crenças nas tradições pré-cristãs ainda perdurassem, principalmente neste contexto herético, de transformações e de conflitos entre laicos e eclesiásticos, como foi a Idade Média central. O mito parece se comportar, semelhantemente às sociedades da Antiguidade, durante o período medieval, como elemento portador e difusor de uma mensagem, isto é, da voz de um coletivo que, ao crer numa história, decodifica a palavra (ouvida, geralmente), ainda que metafórica, que poderia estar intrínseca a esta voz. O mito não é neutro, ele favorece algo ou alguém, assim como, pela interpretação de sua mensagem, prejudica; ele é representação do factível, não do fato. Deve, assim, servir de amparo cautelar ao historiador consciente de seu caráter verossímil, de fácil aceitação e difusão entre os homens e mulheres antigos e medievais.

O mito, como salientado, também foi instrumento de análise aos estudiosos que endossaram a teoria das sociedades ginecocratas pré-históricas ${ }^{31}$, o terceiro elemento aqui abordado. Este debate historiográfico se constitui significativo uma vez que tange na temática das sociedades célticas-consideradas, como foram vistas, de saliente valorização do elemento feminino, segundo muitos estudiosos-a mais provável civilização de origem da legenda tristânica. A expressiva ausência de documentações diretas, em formato escrito, leva o historiador, mais uma vez, a considerar com cautela as tradições mitológicas desse grupo de povos. O conteúdo mitológico que se supõe que seja de origem céltica pode, ademais, ter passado por ressignificações que não revelam, de certa maneira, a essência da mensagem original que circulava através dos recursos orais de comunicação, por exemplo.

Apesar das possíveis ressignificações que esses mitos — originalmente transmitidos via oralidade - tenham sofrido, eles jamais se mostram descartáveis, como já fora aqui salientado. É importante, assim, que se considere, parcialmente, as colocações realizadas pela teoria das sociedades femininas, mas sempre de maneira crítica e que se busque contemplar através de quais tipos de documentações que a teoria é sustentada. A exclusividade da utilização do arcabouço mitológico para sustenta-la não é algo entendido como viável—como muitas críticas ao La Femme Celte ressaltam ${ }^{32}$ — sendo, portanto, de

\footnotetext{
${ }^{31}$ Além dos autores aqui citados, Françoise D’Eaubonne e Jean Markale, o próprio Johan Bachofen utilizouse de um amplo arcabouço mitológico para construção de sua teoria, como foi mostrado. Outra obra de renome dentro da teoria das sociedades ginecocratas é Gerda Lerner, que também se utiliza de relatos mitológicos. Para mais ver: Lerner (1987).

${ }^{32}$ Para as críticas à obra ver: Le Roux-Guyonvarc'h (1974, p. 1034-1035) e Rafroidi (1976. p. 251-253).
} 
Ana Alteparmakian. O mito de Tristão e Isolda inscrito na Antiguidade.

grande validade à consideração do debate a pluralidade das naturezas documentais, sejam elas escritas, pictóricas ou arqueológicas.

A Isolda entendida por Jean Markale não é completamente dispensável, mas também não se coloca como uma análise definitivamente segura pelas razões consideradas acima. Os aspectos entendidos pelo autor como constituintes de uma "concepção céltica" do feminino se originam de uma análise feita por ele mesmo, a partir de uma metodologia comparativa dentro de narrativas de um amplo leque mitológico que especialistas afirmaram ser de origem céltica, porque presentes nas tradições de países cuja territorialidade fora ocupada pelos “celtas" num passado longínquo. É preciso, portanto, adotar sua ideia com cuidado e com olhar atento às possíveis projeções anacrônicas, influenciadas por um contexto acadêmico fervilhante que Markale pode ter realizado ao investigar a caracterização da personagem.

Recebido em 06.02.2020, aprovado em 23.03.2020. 
Mare Nostrum, ano 2020, v. 11, n. 1 .

\section{REFERÊNCIAS BIBLIOGRÁFICAS}

Baccega, M. (2011). Logos do Sacramento. Retórica do Santo Graal. A Sacramentalidade Medieval do Mundo e do Homem na Demanda do Santo Graal de Heidelberg (século XIII). [Tese de Doutorado, USP].

Baccega, M. (2015). “O Santo Graal, o Ciclo de Artur e o mundo moderno". In A Demanda do Santo Graal: o Manuscrito de Heidelberg. Hedra.

Bachofen, J. J. (1861). Das Mutterrecht Eine Untersuchung über die Gynaikokratie der alten Welt nach ihrer religiösen und rechtlichen Natur. Verlag von Krais \& Hoffmann.

Barlow, F. (1955). The Feudal Kingdom of England: 1042-1216. Longmans and Green.

Barros, J. A. (dezembro, 2005). Imaginário, Mentalidades e Psico-História - uma discussão historiográfica. In Revista Labirinto, (vol. 7). UNIR, 1-28.

Bartlett, R. (2000). England under the Norman and Angevin kings: 1075-1225. Oxford: Clarendon Press.

Bédier, J. (2014). O romance de Tristão e Isolda. (Luís Cláudio de Castro e Costa trad.). Martins Fontes.

Blamires, A (2002). Woman defamed and woman defended: An Anthology of Medieval Texts. Clarendon Press, Oxford University Press.

Bloch, R. H. (1994). Misoginia medieval e a invenção do amor romântico ocidental. (C. Moraes, trad.). Editora 34.

Braga, E. S. (2007). Santas e Sedutoras. As heroínas na Bíblia Hebraica. A mulher entre as narrativas bíblica e a literatura Patrística. [Dissertação, Universidade de São Paulo].

Brown, P. (1990). Corpo e sociedade: o homem, a mulher e a renúncia sexual no início do cristianismo. (V. Ribeiro, trad.). Zahar.

Brooke, C. (1961). From Alfred to Henry III (871 - 1272). T. Nelson,

Burkert, W. (1993). Religião grega na época arcaica e clássica. Fundação Calouste Gulbekian. 
Ana Alteparmakian. O mito de Tristão e Isolda inscrito na Antiguidade.

Campbell, J. (2015). Deusas: os mistérios do divino feminino. (S. Rossi, ed. T. Van Acker, trad.). Palas Athena.

Cox, V. \& Ward, J. O. (orgs). (2006). The rhetoric of Cicero in its medieval and early Renaissance commentary tradition. Brill.

Copeland, R. (1995). Rhetoric, Hermeneutics and Translations in the Middle Ages. Cambridge University Press.

Copeland, R. (2016). The Oxford History of Classical Reception in English Literature. Volume I (800-1558). Oxford University Press.

Curtius, E. R. (1996). Literatura europeia e Idade Média Latina. (T. Cabral, \& P. Rónai, trads.). Editora Hucitec e EDUSP.

Daninos, A. M. (1965). Histoire de relations sexuelles. Presses Universitaires de France.

D’Eaubonne, F. (1977). As mulheres antes do patriarcado. Editorial Vega.

Doggett, L. E. (2009). Love Cures: healing and love magic in Old French romances. The Pennsylvania State University Press.

Engels, F. (1985). A origem da família, da propriedade privada e do Estado. (J. S. Paes, trad.). ( $2^{\mathrm{a}}$ ed). Global.

Faletra, M. A. (2014). Wales and the Medieval Colonial Imagination. The Matters of Britain in the Twelfth Century. Palgrave Macmillan.

Ferreira, A. H. (2004). Miniaurélio: o dicionário da língua portuguesa. Coordenação de Margarida dos Anjos e Marina Baird Ferreira. (ver. rev. $6^{\mathrm{a}}$ ed.). Positivo.

Fonseca, P. C. L. (2013). Misoginia, o mal do homem: postulados filosóficos e literários do mundo antigo e do seu legado medieval. Acta Scientiarum: language and culture. Maringá, 35 (1), 75-85.

Foucault, M. (2000) As Palavras e as Coisas: uma arqueologia das Ciências Humanas. (S. T. Muchail, trad.). Martins Fontes.

Georgoudi, S. (1990). Bachofen, o matriarcado e a Antiguidade: reflexões sobre a criação de um mito. In Duby, Georges \& Perrot, Michelle (org.). História das mulheres no Ocidente (v.1). (pp. 569-589) (M. H. C. Coelho, I. M. Vaquinhas, L. Ventura, \& G. Mota, trads.). Edições Afrontamento. 
Mare Nostrum, ano 2020, v. 11, n. 1 .

Gimbutas, M. (1999). The Living Godesses. (M. R. Dexter, ed.). California University Press.

Graves-Brown, C. (2010). Dancing for Hathor: Women in Ancient Egypt. Continuum.

Gurevich, A. J. (1985). Categories of Medieval Culture. (G. L., Campbell, Routledge \& Kegan Paul plc., trad.).

Harper-Bill, C. Houts, E. van. (eds.). (2003). A Companion to the Anglo-Norman World. The Boydell Press.

Hincapié, L. (2013). Yseut: la mère, l'amour, la mort. In Luinguistica y Literatura, 63, $17-34$.

Houts, E. van. (1999). Memory and Gender in Medieval Europe, 900-1200. MacMillan Press.

Johnson, F. F. (2012). Origins of Arthurian Romances. Early Sources for the Legends of Tristan, the Grail and the Abduction of the Queen. North Carolina: MacFarland \& Company.

Júnior, H. F. (2010). A Eva Barbada: ensaios de Mitologia Medieval. EDUSP.

Köhler, E. (1990). La Aventura caballeresca: ideal y realidade en la narrativa cortés. Sirmio,

Le Roux-Guyonvarc'h, F. (1974). Markale (Jean), La femme celte. Revue belge de philologie et d'histoire, 52 (4). Histoire (depuis l'Antiquité) — Geschiedenis (sedert de Oudheid), 1034-1035.

Lerner, G. (1987). The Creation of Patriarchy. Oxford University Press.

Marchello-Nizia, C. (ed.). (1995). Tristan et Yseut: les premières versions europèennes. Éditions Gallimard.

Markale, J. (1969). Les Celtes et la civilization celtique. Mythe et Histoire. Éditions Payot.

Markale, J. (1986). Women of the Celts. (A. Mygind, C. Hauch, P. Henry, trads.). Inner Traditions International, Ltd.

Millet, K. (1970). Sexual Politics. Hupert Hart-Davis. 
Marin Morgante, M. \& Nader, M. B. (28 de julho a $1^{\text {o }}$ de agosto de 2014). O patriarcado nos estudos feministas: um debate teórico. Anais do XVI Encontro Regional de História da Anpuh-Rio: saberes e práticas científicas.

Newstead, H. (1959). The Origin and Growth of the Tristan Legend. In Loomis, Roger Sherman (ed.). Arthurian Literature in the Middle Ages: A Collaborative History (pp. 122-133). Clarendon Press.

Papunen, S. (Juin, 2014). La pensée écoféministe de Françoise D’Eauboone. Mémoire de maîtrise apresenté à l’Université de Tampere.

Paris, G. (1899). Tristan et Iseut . In. Poèmes et légendes du Moyen Âge (pp. 113-180). Societé d'Edition Artistique.

Péron, G. (2016). L'origine du roman de Tristan. Bulletin de la Société archéologique du Finistère, CXLIII, 351-370.

Pilosu, M. (1995). A mulher, a luxúria e a Igreja na Idade Média. Editorial Estampa.

Rafroidi, P. (1976). Jean Markale: La Femme Celte; Women of the Celts, Gordon Cremoseni; Le Roi Arthur et la Société celtique. Études irlandaises, 1, 251-253.

Rossi, A. (2009). J. J. Bachofen y el retorno de las Madres. Acta Poetica, 30 (1), 273293.

Rougemont, D. (1988). O Amor e o Ocidente. (P. Brandi \& C. Brandi Cachapuz, trads.). Edições Guanabara.

Rust, L. D. (2013). A Reforma Papal (1050-1150). Trajetórias e críticas de uma história. EDUFMT.

Sauer, M. M. (2015). Gender in Medieval Culture. Bloomsbury Publisinhg.

Scott, J. (julho-dez. 1995). Gênero: uma categoria útil de análise histórica. Educação \& Realidades, Porto Alegre, 20 (2), 71-99.

Schoepperle, G. (1913). Tristan and Isolt: a study of the sources of the romance. (2 volumes). Joseph Baer \& Co. Londres: David Nutts, publisher.

Stafford, P. (1994). Women and the Norman Conquest. Transactions of the Royal Historial Society, 4, pp. 221-249. 
Mare Nostrum, ano 2020, v. 11, n. 1 .

Tilly, L. A. (1994). Gênero, História das Mulheres e História Social. (R. A. Vieira, trad.). Cadernos Pagu 3, 29-62.

Vernant, J.-P. (2009). Mito e Religião na Grécia Antiga. (J. A. D’Avila Melo, trad.). Martins Fontes.

Waddell, J. (2018). Myth and Materiality. Oxbow Books.

Zumthor, P. (1993). A letra e a voz: a "literatura" medieval. Companhia das Letras. 
Ana Alteparmakian. O mito de Tristão e Isolda inscrito na Antiguidade.

\section{The MYTH Of Tristan AND ISOLDE INSCRIBED In ANTIQUITY: Theoretical And Methodological Contributions Beyond The \\ Middle Ages}

Ana Carolina Pedroso Alteparmakian

ABSTRACT

The article proposes a theoretical and methodological survey, as well as a historiographic one, of three elements that permeate the content of the myth of Tristan and Isolde. The first seeks to analyze the meaning of the term gender, as an analytical tool to the idea of "medieval woman"; the second aims to discuss the understanding and the dissemination of myths during antiquity and the middle ages. Finally, the interpretation formulated by Jean Markale in La Femme Celte will be addressed: supported by the theory of the existence of prehistoric gynecocratic societies, the mythologist analyses the character Isolde and identifies it with feminine aspects from celtic societies. We will discuss, therefore, the importance of these three elements for a deeper knowledge of the Tristanic myth, a narrative based on assumptions prior to the Middle Ages, the time of its (re) emergence.

KEYWORDS

Gender; romance; women; mythology; patriarchy. 